\title{
Gastrointestinal exposed endoscopic full-thickness resection in the era of endoscopic suturing: a retrospective single-center case series
}

\author{
Antonino Granata ${ }^{1}$, Alberto Martino ${ }^{2}$, Michele Amata $^{1}$, Dario Ligresti ${ }^{1}$, Mario Traina ${ }^{1}$ \\ ${ }^{1}$ Endoscopy Service, Department of Diagnostic and Therapeutic Services, IRCCS - ISMETT, Palermo, Italy \\ 2Department of Gastroenterology and Digestive Endoscopy, AORN “Antonio Cardarelli”, Napoli, Italy
}

Videosurgery Miniinv 2021; 16 (2): 321-328

DOI: https://doi.org/10.5114/wiitm.2021.104496

\begin{abstract}
Introduction: Exposed endoscopic full thickness resection (EFTR) is a minimally invasive technique that has shown promising efficacy and safety in the removal of both gastrointestinal (GI) submucosal tumors (SMTs) arising from the muscularis propria (MP) and select epithelial tumors (ETs) unsuitable for conventional resection techniques. Given the chance of realizing endosurgical full-thickness suturing, the Endoscopic Suturing System (ESS) can be used to close wall defects in this setting. However, data concerning its use in EFTR are still limited.

Aim: This study was conducted to evaluate the safety and efficacy of exposed EFTR with defect closure using the ESS for the removal of both GI SMTs and select ETs unsuitable for conventional resection techniques.

Material and methods: This was a retrospective, single-center, observational cohort study of patients who underwent Gl exposed EFTR.

Results: Seven patients ( $M: F 6: 1)$ with a mean age of $56 \pm 14.5$ years were identified. The indications were MP-originating SMTs of the stomach $(n=2)$ and duodenum $(n=2)$, and from submucosa of the rectum $(n=1)$, and $2 E T$ s of the rectum. Exposed EFTR and defect closure were successfully performed in 6/7 patients. One case was converted to laparoscopic gastric wedge resection due to technical unfeasibility. We performed an $R O$ resection in all cases, with the exception of 1 case of rectal EFTR. No macroscopic recurrence was detected at 6-month endoscopic follow-up. Conclusions: GI exposed EFTR with defect closure by the ESS appears to be feasible, effective, and safe in referral centers. Further studies are necessary to clarify the role of the ESS for post-EFTR wall defect closure.
\end{abstract}

Key words: NOTES, endoscopic full thickness resection, endoscopic suturing system, exposed endoscopic full-thickness resection.

\section{Introduction}

Exposed endoscopic full-thickness resection (EFTR), previously reported as pure free-hands or standard EFTR, without laparoscopic assistance is a scarless natural orifice transluminal endoscopic surgery (NOTES) technique that is emerging as a promising approach, with good efficacy and safety in the resection of both muscularis propria (MP)-orig- inating submucosal tumors (SMTs) and select epithelial tumors (ETs) unsuitable for conventional endoscopic resection [1-6]. In exposed EFTR, the full-thickness resection is followed by subsequent Gl defect closure. Thus, the term "exposed" is derived from the temporary exposure of the peritoneal cavity to the Gl lumen [7]. The mainstay of exposed EFTR is a safe wall defect closure after the excision in order 
to prevent peritonitis and further surgical interventions. Currently, this is achieved principally through the use of standard through-the-scope (TTS) clips [8] or clips combined with endoloops [9, 10]. Endoscopic suturing devices, such as the OverStitch Endoscopic Suturing System (ESS) (Apollo Endosurgery, Austin, Texas, USA), that allow placement of durable full-thickness suturing that incorporates the muscle layer and results in a more stable construct, have been successfully used to suture gastrointestinal (GI) wall defects $[11,12]$. However, data regarding their use in the exposed EFTR procedure are limited.

\section{Aim}

This study aimed to investigate the efficacy, safety, and feasibility of exposed EFTR followed by defect closure using the OverStitch ESS for select GI lesions.

\section{Material and methods}

\section{Study design and patients}

This study was a retrospective, observational, open-label, single-arm, consecutive case series conducted at a single tertiary-referral center from September 2018 to July 2019. A consecutive cohort of patients who underwent exposed EFTR without laparoscopic assistance with subsequent and sametime defect closure using the OverStitch for GI SMTs or ETs unsuitable for conventional endoscopic resection was included in our study. The inclusion criteria for patient selection were as follows: (1) gastric or duodenal SMTs arising from the MP, as confirmed by endoscopic ultrasound (EUS), with tumor diameter larger than $20 \mathrm{~mm}$ and/or presence of symptoms, gastrointestinal stromal tumor proven by preoperative histopathological examination, evidence of tumor growth during follow-up or patients' preference; (2) rectal ETs unsuitable for conventional endoscopic resection (e.g., recurrent adenomas with negative lifting sign, incomplete resected non-lifting adenomas and T1-carcinomas incidentally resected using standard endoscopic techniques and with histological submucosal infiltration depth that was not assessable); (3) rectal SMTs with preoperative histological diagnosis of neuroendocrine tumor.

Exclusion criteria were as follows: pregnancy, patients < 18 years of age, failure to provide informed consent, coagulopathy (international normalized ratio > 1.5 and/or platelets $<40000 / \mu \mathrm{l})$, metastatic disease on computed tomography (CT) and/or EUS, lesion size > $50 \mathrm{~mm}$, SMTs with high-risk EUS features (i.e., irregular borders, cystic spaces, ulceration, echogenic foci, and heterogeneity).

Data were extracted for demographics, lesion features, RO resection (i.e., negative vertical and lateral resection margins at histology) status, operation time (i.e., from submucosal injection to endoscopic suturing closure completion), surgical conversions (due to technical unfeasibility of the procedure and/ or occurrence of adverse events (AEs) not amenable to endoscopic treatment), major AEs (i.e., delayed bleeding, delayed perforation, peritonitis, abdominal abscess, and abdominal infection), and length of hospital stay. Descriptive statistical analysis of the data, including percentage and mean, are reported.

IRRB approval was not needed for the study, and written informed consent was obtained from all patients.

\section{Endoscopic equipment and accessories}

Full-thickness resection was performed using a standard single-channel endoscope with a transparent cap (GIF-1TH190 plus D-201-11804, Olympus Europe, Hamburg, Germany Olympus) attached to its front, and an O-type HybridKnife (Erbe Elektromedizin, Tübingen, Germany). A double-channel endoscope (GIF2T160; Olympus Europe, Hamburg, Germany) preloaded with an OverStitch ESS (Apollo Endosurgery, Austin, Texas, USA) was used for wall defect suturing closure.

\section{Pre-operative evaluation and procedures}

All patients underwent pre-operative EUS and CT in order to characterize the lesion and exclude malignancy. All the procedures were performed with the patients under general anesthesia by a single, experienced therapeutic endoscopist (A.G.), whose experiences included more than 500 upper and lower Gl endoscopic submucosal dissections (ESDs), and more than 100 procedures involving the use of the ESS. In all the cases, an operating room with an oncall abdominal surgeon was preventively activated in case of exposed EFTR failure or intra-procedural AEs not amenable endoscopically. Informed consent for both endoscopic and surgical operations was obtained from the patients.

Only carbon dioxide was used for insufflation. All patients received a single dose of prophylactic broad spectrum antibiotic administered intravenously immediately before the procedure. 
Exposed EFTR was performed as previously described [8]. Wall defect closure was achieved using the ESS in all cases. The procedure systematically involved (A) submucosal injection followed by precutting the mucosal and submucosal layer around the lesion; (B) exposed EFTR of the lesion and creation of an "active perforation" after draining intraluminal fluid; (C) capnoperitoneum management through a percutaneously inserted 20-gauge angiocatheter in the case of upper Gl procedures; (D) single-channel endoscope removal and insertion of a double-channel endoscope preloaded with an ESS in order to perform full-thickness suturing closure by creation of either a continuous suture line or separated stitches (Photo 1).

\section{Post-operative management and follow-up}

All patients were admitted to the institute for post-procedure monitoring of AEs and kept nil per os the day of the operation. In cases of upper GI procedures, patients were allowed liquid diet on day 1 , soft
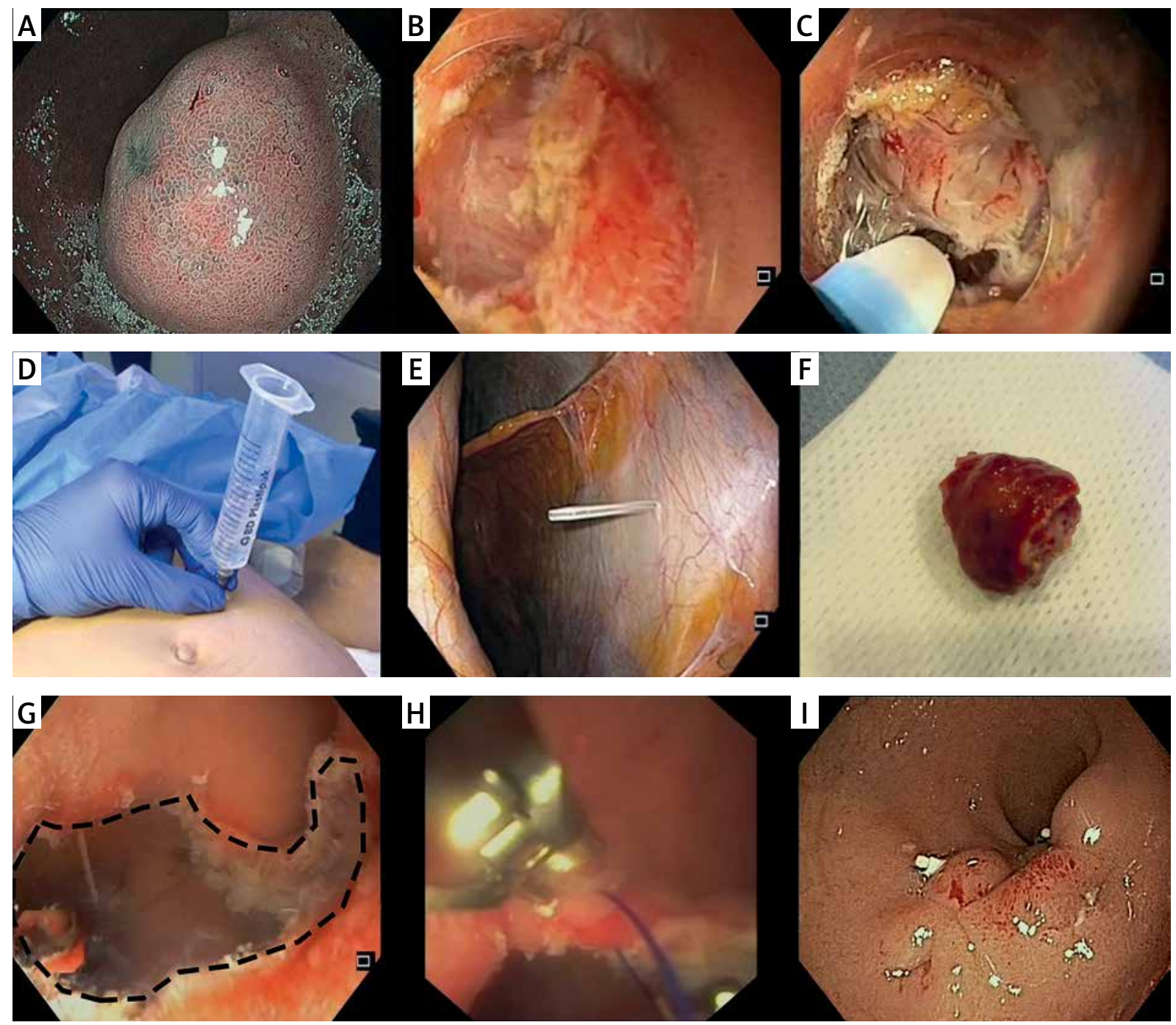

Photo 1. Technical illustration of exposed endoscopic full-thickness resection (EFTR) followed by defect closure using endoscopic suturing system (ESS). A - Magnifying endoscopy with narrow-band imaging showing a submucosal lesion of the duodenal bulb with an erosion on the top. B - Precutting and removal of the mucosal and submucosal layer after submucosal injection, in order to expose the tumor. $\mathbf{C}$ - Exposed EFTR of the tumor and creation of "active perforation." D, E - Capnoperitoneum management using percutaneously inserted angiocatheter. F-Macroscopic histological specimen. G - Duodenal wall defect after the full-thickness resection. $\mathbf{H}$ - Defect closure with the OverStitch ESS. I - final apposition of the tissue margins 
diet on day 3, and advancement of diet as tolerated thereafter. Conversely, soft diet was begun on day 1 following lower GI procedures. Post-EFTR medication included intravenous infusions of proton pump inhibitors (after upper Gl procedures only) and antibiotics. Post-operative investigations to check for the adequacy of wall defect closure were not routinely performed. Patients were closely observed with clinical and laboratory examinations for any signs of peritonitis and/or Gl bleeding. Patients were discharged home in the absence of specific complaints.

Follow-up endoscopy was performed 1 and 6 months after the procedure to observe the wound healing and exclude macroscopic recurrence. Subsequently, follow-up strategies were based on the results of histopathological examination.

\section{Results}

Seven patients $(M: F 6: 1)$ with a mean age of $56 \pm 14.5$ years were identified. The indications were as follows: SMTs arising from the MP of the stomach $(n=2)$ and duodenum $(n=2)$, and from submucosa of the rectum $(n=1)$; ETs $(n=2)$ of the rectum, including one recurrent non-lifting adenoma in a post-endoscopic mucosal resection (EMR) scar, and one $\mathrm{T} 1$ carcinoma incidentally resected by EMR, without clear histopathological depth of submucosal invasion (Table I). The mean lesion size assessed by EUS was $25 \pm 9.9 \mathrm{~mm}$ (range: $15-40$ ), and the mean procedure time $164 \pm 41 \mathrm{~min}$ (range: 110-254). Exposed EFTR was successfully performed in 6 of the 7 patients. Defect closure with the ESS was effective in all cases (6/6 patients). One case was converted into laparoscopic gastric wedge resection during the same anesthesia due to technical unfeasibility for completion of the resection. Histopathological examination showed grade 1 neuroendocrine tumors $(n=2)$ [13], low risk gastrointestinal stromal tumor $(n=1)$ [14], pancreatic heterotopia $(n=2)$, low-grade dysplasia adenoma $(n=1)$, and T2 adenocarcinoma

Table I. Clinicopathological characteristics and outcomes of exposed endoscopic full-thickness resection followed by defect closure with the endoscopic suturing system

\begin{tabular}{|c|c|c|c|c|c|c|c|}
\hline Parameter & Case 1 & Case 2 & Case 3 & Case 4 & Case 5 & Case 6 & Case 7 \\
\hline Age & 75 & 48 & 62 & 26 & 54 & 66 & 59 \\
\hline Gender & Male & Male & Male & Female & Male & Male & Male \\
\hline $\begin{array}{l}\text { Lesion } \\
\text { location }\end{array}$ & $\begin{array}{l}\text { Duodenal bulb } \\
\text { (anterior wall) }\end{array}$ & $\begin{array}{l}\text { Gastric body } \\
\text { (anterior wall) }\end{array}$ & $\begin{array}{l}\text { Duodenal bulb } \\
\text { (inferior wall) }\end{array}$ & $\begin{array}{c}\text { Gastric antrum } \\
\text { (incisura } \\
\text { angularis) }\end{array}$ & $\begin{array}{c}\text { Rectum } \\
\text { (posterior wall) }\end{array}$ & $\begin{array}{c}\text { Rectum } \\
\text { (posterior wall) }\end{array}$ & $\begin{array}{c}\text { Rectum } \\
\text { (posterior wall) }\end{array}$ \\
\hline $\begin{array}{l}\text { Lesion size } \\
{[\mathrm{mm}]}\end{array}$ & 18 & 15 & 30 & 18 & 40 & 40 & 20 \\
\hline $\begin{array}{l}\text { Depth of } \\
\text { invasion } \\
\text { (EUS) }\end{array}$ & IV Layer & IV Layer & IV Layer & IV Layer & III Layer & II Layer & III Layer \\
\hline Pathology & NET G1 & $\begin{array}{c}\text { Ectopic } \\
\text { pancreas }\end{array}$ & GIST & $\begin{array}{c}\text { Ectopic } \\
\text { pancreas }\end{array}$ & $\begin{array}{l}\text { Invasive } \\
\text { adenoca }\end{array}$ & $\begin{array}{c}\text { LGD } \\
\text { adenoma }\end{array}$ & NET G1 \\
\hline $\begin{array}{l}\text { En bloc } \\
\text { resection }\end{array}$ & Yes & Yes & Yes & Yes & Yes & Yes & Yes \\
\hline RO resection & Yes & Yes & Yes & Yes & No & Yes & Yes \\
\hline $\begin{array}{l}\text { Surgical } \\
\text { conversion }\end{array}$ & No & No & No & Yes & No & No & No \\
\hline $\begin{array}{l}\text { Major adverse } \\
\text { events }\end{array}$ & None & None & None & None & None & None & None \\
\hline $\begin{array}{l}\text { Procedure } \\
\text { time [min] }\end{array}$ & 148 & 147 & 145 & 254 & 166 & 181 & 110 \\
\hline $\begin{array}{l}\text { Length of } \\
\text { hospital stay } \\
\text { [days] }\end{array}$ & 3 & 4 & 4 & 7 & 4 & 3 & 3 \\
\hline
\end{tabular}

EUS - endoscopic ultrasonography, GIST - gastrointestinal stromal tumor, adenoca - adenocarcinoma, LGD - low-grade dysplasia, NET G1 - neuroendocrine tumor grade 1. 
$(n=1)$. We performed an R0 resection in all cases except for 1 case of rectal EFTR, previously treated by standard endoscopic mucosal resection and with evidence of invasive carcinoma infiltrating the MP. No major AEs were observed. Mean post-procedure hospitalization was $4 \pm 1.31$ days (range: $3-7$ ).

At 1-and 6-month surveillance endoscopy, wound healing was detected in 6 out of 7 cases, including the gastric case converted into laparoscopic surgery. Neither macroscopic residual tumor nor tumor recurrence was observed (Photo 2). One-month endoscopic follow-up was not performed in the rectal case, in which subsequent surgery was done due to invasive adenocarcinoma. For the 2 cases of pancreatic heterotopia no further follow-up was done. For all the remaining cases, no local or systemic recurrence was observed during a mean follow-up period of 13.2 months (range: 9-18 months).

\section{Discussion}

EFTR was first described in 1998 by Suzuki et al. [15]. In 2001, the same group reported the effectiveness of EFTR using a ligation device for the treatment of 2 rectal tumors and 1 duodenal neuroendocrine tumor in humans [16]. A few years later, Ikeda et al. reported EFTR using the ESD technique on a porcine stomach [17], and Zhou et al. translated this technique into clinical practice (26 cases of gastric SMTs) [8].

Thereafter, exposed EFTR without laparoscopic control emerged as a promising, safe, and effective evolution technique for the resection of challenging ETs and deep SMTs through the GI tract, especially gastric MP-originating SMTs [1-6]. Exposed EFTR is an evolving "cut then close" NOTES technique providing the intentional creation of an active perforation for a complete endoscopic resection followed by wall patency restoration. Thus, effective defect closure is a crucial step of the procedure, with a key role in the final outcome. In this setting, different closure methods have been successfully reported in large series, mainly TTS clips, clips combined with endoloops, and over-the-scope (OTS) clips $[8-10,18]$. The main limitation of TTS and OTS clip approaches is their inability to close wall defects larger than 10 and $25 \mathrm{~mm}$, respectively [19].

Though technically demanding, effective larger defect closure with either different clips combined with endoloop techniques $[9,10]$ or the omental-patch method has been reported [20-22].
Following the advent of exposed EFTR, the non-exposed EFTR technique was introduced. Technically, the resection of the lesion is performed after the plication of the Gl tract wall with dedicated full-thickness suturing devices, mainly represented by the OTSC system (Ovesco Endoscopy GmbH, Tübingen, Germany). The advantages of this "close then cut" technique consist principally in the potential avoidance of intra-peritoneal dissemination of tumor cells, and potential risk of infection. In addition, this approach has greater technical simplicity, with faster operating time. However, compared with exposed EFTR, the OTSC system is limited by a lower resection RO rate, likely due to the impossibility of a "real-time" and direct visualization of the perimetral cutting margins. Also, the clip cannot be reverted once released, and is limited to small lesions (<25 mm) [5].

In exposed EFTR, a full-thickness defect closure is strongly advised by the American Society for Gastrointestinal Endoscopy [7]. This is not achievable by standard clip closure methods, which allow mucosal and submucosal approximation only, due to the superficial bite of the clips [23]. Conversely, suturing closure by the use of ESS creates a full-thickness "surgical" suture through all layers of the GI wall, allowing secure closure of even large defects [24-26]. However, the efficacy and safety of OverStitch ESS for closure of post-EFTR wall defects have been reported only in a handful of case reports and 1 case series [27-32].

The concept of full-thickness suturing closure is of particular interest when performing exposed EFTR in ill-advised locations, such as the duodenum and colon-rectum. In fact, in these sites, ineffective defect closure is associated with higher morbidity and mor-
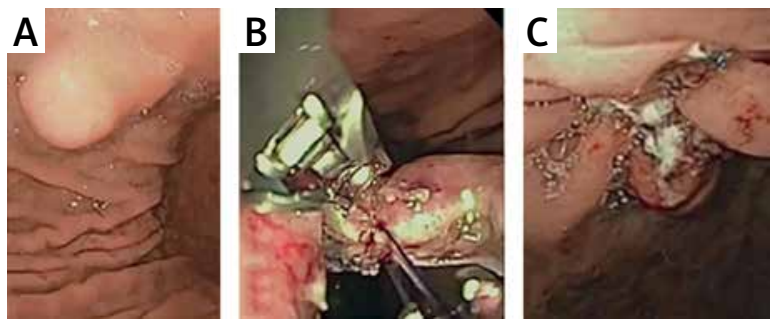

Photo 2. Successful exposed endoscopic fullthickness (EFTR) resection of a submucosal tumor of the gastric body. A - Pre-operative evaluation, $\mathbf{B}$ - endoscopic suturing of the post-EFTR gastric wall defect using the OverStitch, $\mathbf{C}$ - effective suturing closure of the post-EFTR gastric wall defect 
tality than elsewhere in the GI tract. Indeed, evidence concerning exposed EFTR for duodenal or colorectal lesions is lacking due to concerns about safe and reliable defect closure achievement [25, 28, 33, 34].

In our case series wall defect closure using the Overstitch ESS was feasible and effective in all patients (6/6), including two duodenal defects (18 and $30 \mathrm{~mm}$, respectively) and three rectal defects (40, 40, and $20 \mathrm{~mm}$, respectively). No major AEs occurred, including delayed perforation and peritonitis. Only one gastric case was converted into laparoscopic wedge resection. After $75 \%$ of the resection, completion of the EFTR appeared technically unfeasible. Attempts at thread-with-clip countertraction, as previously reported $[35,36]$, were not effective in obtaining successful triangulation. Endoscopic peritoneal exploration showed the extraluminal growth pattern of the gastric SMT, and its close contact with the left liver lobe. The patient was previously informed that in case of EFTR failure, the standard laparoscopic approach would be performed during the same general anesthesia as a step-up approach. No major AEs occurred after the laparoscopy, RO resection was achieved, and the patient was discharged on day 7 .

In 2 cases, final histological diagnosis was heterotopic pancreas. In both cases pre-operative EUS-guided fine needle biopsy was performed. However, cytohistological examination was inconclusive, and both patients refused long-term endoscopic surveillance. Thus, exposed EFTR was proposed after multidisciplinary evaluation. As previously reported, indications for EFTR can include undiagnosed lesions in younger patients for whom the risk of resection might be outweighed by the benefit of avoiding long-term surveillance [37].

$R 1$ resection was observed in only one rectal EFTR, which was performed for re-resection of a T1 carcinoma incidentally diagnosed in an EMR-treated lesion. Submucosal infiltration depth could not be determined accurately by the pathologist, and subsequent pre-operative EUS did not show clear MP infiltration. In this clinical setting, EFTR may represent an excellent diagnostic technique and, in the case of low-risk tumors (submucosal infiltration depth $<1000 \mu \mathrm{m}, \mathrm{G} 1$ or G2, absence of lymphatic vessel invasion, R0 resection), it is even therapeutic [38]. Thus, EFTR was performed. Unfortunately, the final histopathological examination was consistent with invasive adenocarcinoma infiltrating the MP and the patient underwent subsequent surgery.
Post-EFTR wall defect closure using the OverStitch was performed with either interrupted or continuous sutures according to the size, shape, and location of the defect [39].

The use of the OverStitch ESS for duodenal post-EFTR defect closure appeared feasible in experienced hands. However, compared with its use within the gastric or rectal cavity, endoscopic suturing within the duodenum seemed technically more demanding, mainly due to the limited working space.

In our opinion, the worldwide diffusion in clinical practice of exposed EFTR and other NOTES techniques during the last 15 years may be partly due to the unavailability of endoscopic suturing devices. The recent advent of such devices might represent a new start for NOTES procedures. ESS could be considered the natural evolution of the endosurgical technique of exposed EFTR, providing safe and effective full-thickness defect closure, and thus expanding its potential usefulness. Its role as a firstline endosurgical procedure, including in an eventual step-up approach for the management of select GI tumors in referral centers, appears particularly intriguing [40]. High morbidity and mortality associated with major surgery, especially of the duodenum, justify active research in this field.

\section{Conclusions}

Exposed EFTR without laparoscopic assistance, followed by suturing closure using the OverStitch, appears to be feasible, effective, and safe for the management of select epithelial and subepithelial tumors of the Gl tract. Further prospective and randomized studies are needed to clarify the role of Overstitch ESS for post-EFTR wall defect closure.

\section{Conflict of interest}

The authors declare no conflict of interest.

\section{References}

1. Granata A, Martino A, Amata M, et al. Efficacy and safety of gastric exposed endoscopic full-thickness resection without laparoscopic assistance: a systematic review. Endosc Int Open 2020; 8: E1173-82.

2. Cai M, Zhou P, Lourenço LC, Zhang D. Endoscopic full-thickness resection (EFTR) for gastrointestinal subepithelial tumors. Gastrointest Endosc Clin N Am 2016; 26: 283-95.

3. Jain D, Mahmood E, Desai A, Singhal S. Endoscopic full thickness resection for gastric tumors originating from muscularis propria. World J Gastrointest Endosc 2016; 8: 489-95. 
4. Cai MY, Martin Carreras-Presas F, Zhou PH. Endoscopic fullthickness resection for gastrointestinal submucosal tumors. Dig Endosc 2018; 30 Suppl 1: 17-24.

5. Mori H, Kobara H, Nishiyama N, Masaki T. Current status and future perspectives of endoscopic full-thickness resection. Dig Endosc 2018; 30 Suppl 1: 25-31.

6. Zhang X, Modayil R, Criscitelli T, Stavropoulos SN. Endoscopic resection for subepithelial lesions-pure endoscopic full-thickness resection and submucosal tunneling endoscopic resection. Transl Gastroenterol Hepatol 2019; 4: 39.

7. ASGE Technology Committee, Aslanian HR, Sethi A, et al. ASGE guideline for endoscopic full-thickness resection and submucosal tunnel endoscopic resection. VideoGIE. 2019; 4: 343-50.

8. Zhou PH, Yao LQ, Qin XY, et al. Endoscopic full-thickness resection without laparoscopic assistance for gastric submucosal tumors originated from the muscularis propria. Surg Endosc 2011; 25: 2926-31.

9. Shi Q, Chen T, Zhong YS, et al. Complete closure of large gas tric defects after endoscopic fullthickness resection, using endoloop and metallic clip interrupted suture. Endoscopy 2013; 45: 329-34.

10. Ye LP, Yu Z, Mao XL, et al. Endoscopic full-thickness resection with defect closure using clips and an endoloop for gastric subepithelial tumors arising from the muscularis propria. Surg Endosc 2014; 28: 1978-83.

11. Kantsevoy SV, Bitner M, Hajiyeva G, et al. Endoscopic management of colonic perforations: clips versus suturing closure (with videos). Gastrointest Endosc 2016; 84: 487-92.

12. Stavropoulos SN, Modayil R, Friedel D. Current applications of endoscopic suturing. World J Gastrointest Endosc 2015; 7: 777-89.

13. Rindi G, Arnold R, Bosman FT, et al. Nomenclature and classification of neuroendocrine neoplasms of the digestive system. In: WHO Classification Tumours of the Digestive System. $4^{\text {th }} \mathrm{ed}$. Bosman TF, Carneiro F, Hruban RH, Theise ND (eds). International Agency for Reseach on Cancer (IARC), Lyon 2010; 13-4.

14. von Mehren M, Randall RL, Benjamin RS, et al. Soft Tissue Sarcoma, Version 2. 2018, NCCN Clinical Practice Guidelines in Oncology. J Natl Compr Canc Netw 2018; 16: 536-63.

15. Suzuki H, Okuwaki S, Ikeda K, et al. Endoscopic full-thickness resection (EFTR) and waterproof defect closure (ENDC) for improvement of curability and safety in endoscopic treatment of early gastrointestinal malignancies. Prog Dig Endosc 1998; 52: 49-53.

16. Suzuki H, Ikeda K. Endoscopic mucosal resection and full thickness resection with complete defect closure for early gastrointestinal malignancies. Endoscopy 2001; 33: 437-9.

17. Ikeda K, Mosse CA, Park PO, et al. Endoscopic full-thickness resection: circumferential cutting method. Gastrointest Endosc 2006; 64: 82-9.

18. Guo J, Liu Z, Sun S, et al. Endoscopic full-thickness resection with defect closure using an over-the-scope clip for gastric subepithelial tumors originating from the muscularis propria. Surg Endosc 2015; 29: 3356-62.

19. Manta R, Manno M, Bertani H, et al. Endoscopic treatment of gastrointestinal fistulas using an over-the-scope clip (OTSC) device: case series from a tertiary referral center. Endoscopy 2011; 43: 545-8.
20. Hashiba K, Carvalho A, Diniz G, et al. Experimental endoscopic repair of gastric perforations with an omental patch and clips. Gastrointest Endosc 2001; 54: 500-4.

21. Minami S, Gotoda T, Ono H, et al. Complete endoscopic closure of gastric perforation induced by endoscopic resection of early gastric cancer using endoclips can prevent surgery (with video). Gastrointest Endosc 2006; 63: 596-601.

22. Wu CR, Huang LY, Guo J, et al. Clinical control study of endoscopic full-thickness resection and laparoscopic surgery in the treatment of gastric tumors arising from the muscularis propria. Chin Med J 2015; 128: 1455-9.

23. Mangiavillano B, Viaggi P, Masci E. Endoscopic closure of acute iatrogenic perforations during diagnostic and therapeutic endoscopy in the gastrointestinal tract using metallic clips: a literature review. J Dig Dis 2010; 11: 12-8.

24. Kantsevoy SV, Bitner M, Hajiyeva G, et al. Endoscopic management of colonic perforations: clips versus suturing closure (with videos). Gastrointest Endosc 2016; 84: 487-93.

25. Pauli EM, Delaney CP, Champagne B, et al. Safety and effectiveness of an endoscopic suturing device in a human colonic treat-and-resect model. Surg Innov 2013; 20: 594-9.

26. Stavropoulos SN, Modayil R, Friedel D. Current applications of endoscopic suturing. World J Gastrointest Endosc 2015; 7 : 777-89.

27. Andalib I, Yeoun D, Reddy R, et al. Endoscopic resection of gastric gastrointestinal stromal tumors originating from the muscularis propria layer in North America: methods and feasibility data. Surg Endosc 2018; 32: 1787-92.

28. Azzolini F, Cecinato P, Iori V, et al. Endoscopic full-thickness resection for suspected residual rectal neuroendocrine tumor and closure of the defect with a new suturing system. Endoscopy 2015; 47 Suppl 1: E556-7.

29. Xu MM, Angeles A, Kahaleh M. Endoscopic full-thickness resection of gastric stromal tumor: one and done. Endoscopy 2018; 50: E42-3.

30. Granata A, Bisello M, Cipolletta F, et al. Endoscopic wedge gastrectomy of a gastric subepithelial tumor and closure of the gastric wall defect with the overstitch suturing system. Surg Innov 2018; 25: 542-3.

31. Granata A, Amata M, Ligresti D, et al. Underwater full-thickness resection of a duodenal bulb gastrointestinal stromal tumor with OverStitch defect repair. Endoscopy 2019; 51: E207-8.

32. Dedania B, Mistry T, Buryanek J, Singhal S. Endoscopic full-thickness resection of a gastric subepithelial tumor. VideoGIE 2018; 3: $79-80$.

33. Xu M, Wang XY, Zhou PH, et al. Endoscopic full-thickness resection of colonic submucosal tumors originating from the muscularis propria: an evolving therapeutic strategy. Endoscopy 2013; 45: 770-3.

34. Ren Z, Lin SL, Zhou PH, et al. Endoscopic full-thickness resection (EFTR) without laparoscopic assistance for nonampullary duodenal subepithelial lesions: our clinical experience of 32 cases. Surg Endosc 2019; 33: 3605-11.

35. Lu J, Jiao T, Li Y, et al. Facilitating retroflexed endoscopic fullthickness resection through loop-mediated or rope-mediated countertraction (with videos). Gastrointest Endosc 2016; 83: 223-8. 
36. Jeon WJ, You IY, Chae HB, et al. A new technique for gastric endoscopic submucosal dissection: peroral traction-assisted endoscopic submucosal dissection. Gastrointest Endosc 2009; 69: 29-33.

37. Zhang X, Modayil R, Criscitelli T, Stavropoulos SN. Endoscopic resection for subepithelial lesions-pure endoscopic full-thickness resection and submucosal tunneling endoscopic resection. Transl Gastroenterol Hepatol 2019; 4: 39.

38. Schmidt A, Meier B, Caca K. Endoscopic full-thickness resection: current status. World J Gastroenterol 2015; 21: 9273-85.

39. Juzgado D, Sanchez-Yague A. The use of the overstitch beyond bariatric endoscopy: a pictorial description. Gastrointest Endosc Clin N Am 2020; 30: 173-85.

40. Granata A, Martino A, Amata M, et al. Conversion to laparoscopy in gastric endoscopic full-thickness resection: adverse event or routine step-up approach? Endoscopy 2020; 52: E130-1.

Received: 29.07.2020, accepted: 26.10.2020. 